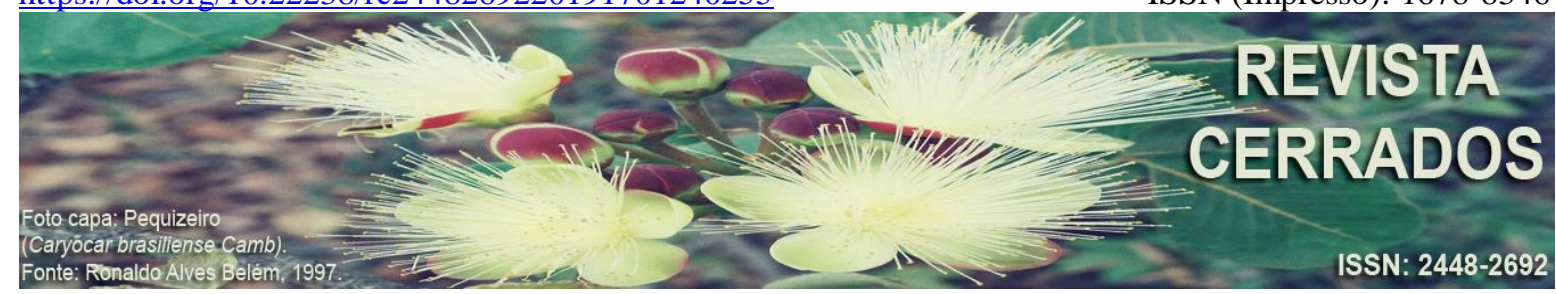

\title{
\#VEMPRARUA: jornadas de um espaço em rede
}

\section{\#VEMPRARUA: journeys of a space in network}

\section{\#VEMPRARUA: jornadas de un espacio en red}

\author{
Gustavo Souza Santos \\ Centro Universitário FIPMoc - UNIFIPMoc \\ E-mail: < gustavo.ccpv@gmail.com>.
}

\begin{abstract}
RESUMO
As jornadas de junho se constituíram como um movimento de insurgência disposto sobre o Brasil no período de junho de 2013, com base nas iniciativas do MPL em protesto contra a tarifa do transporte público em São Paulo, mas cujo escopo se ampliou e abarcou uma série de demandas sociais cuja origem é o âmago da sociedade brasileira na extensão e nas particularidades do território nacional. Na dinâmica dos atos, redes de comunicação alternativa e autônoma foram instrumentos de movimentação, informação e coesão das manifestações, por meio de dispositivos e redes sociais. A proposta deste estudo foi refletir as dinâmicas das Jornadas de Junho, considerando a dimensão do ciberespaço como elemento aglutinador de práticas socioespaciais e de insurgência, na busca de uma aproximação entre Geografia e ciberespaço no contexto do exame do caso em questão.
\end{abstract}

Palavras-chave: Jornadas de Junho. Movimentos Sociais. Espaço. Ciberespaço. Rede.

\begin{abstract}
The June days were constituted as an insurgency movement arranged over Brazil in the period of June 2013, based on the MPL initiatives in protest against the São Paulo public transportation fare, but whose scope has been expanded and encompassed a series of social demands whose origin is the core of Brazilian society in the extension and particularities of the national territory. In the dynamic of the acts, alternative and autonomous communication networks were instruments of movement, information and cohesion of the manifestations, through devices and social networks. The purpose of this study was to reflect the dynamics of the June Conference, considering the dimension of cyberspace as an agglutinating element of socio-spatial and insurgency practices, in the search for an approximation between Geography and cyberspace in the context of the examination of the case in question.
\end{abstract}

Keywords: June Jorneys. Social Movements. Space. Cyberspace. Network. 
SANTOS, G. S.

\#Vemprarua: jornadas de um espaço em rede

\section{RESUMEN}

Las jornadas de junio se constituyeron como un movimiento de insurgencia dispuesto sobre Brasil en el período de junio de 2013, con base en las iniciativas del MPL en protesta contra la tarifa del transporte público en São Paulo, pero cuyo alcance se amplió y abarcó una serie de las demandas sociales cuyo origen es el núcleo de la sociedad brasileña en la extensión y en las particularidades del territorio nacional. En la dinámica de los actos, redes de comunicación alternativa y autónoma fueron instrumentos de movimiento, información y cohesión de las manifestaciones, por medio de dispositivos y redes sociales. La propuesta de este estudio fue reflejar las dinámicas de las Jornadas de Junio, considerando la dimensión del ciberespacio como elemento aglutinante de prácticas socioespaciales y de insurgencia, en la búsqueda de una aproximación entre Geografía y ciberespacio en el contexto del examen del caso en cuestión.

Palabras clave: Jornadas de Junio. Movimientos Sociales. Espacio. Ciberespacio. Red.

\section{INTRODUÇÃO}

Em junho de 2013, o Brasil acompanharam nas Jornadas de Junho uma série de eventos de insurgência. Atos se difundiram pelos 26 estados brasileiros e o Distrito Federal, cobrindo 538 municípios (figura 1), entre eles, 12 capitais, regiões metropolitanas e cidades de maior e menor porte, compreendendo cerca de 2,7 milhões de participantes no período de protestos $^{1}$. Foi possível ainda acompanhar reflexos das manifestações em 73 cidades no exterior ${ }^{2}$.

$\mathrm{Na}$ dinâmica dos atos, redes de comunicação alternativa e autônoma foram instrumentos de movimentação, informação e coesão das manifestações, por meio de dispositivos e redes sociais. Postagens, vídeos, imagens, hashtags e insurgência. Não apenas as ruas, os espaços de governança e os cenários da paisagem urbana foram apropriados e escoaram mensagens de protesto nas jornadas de junho.

\footnotetext{
${ }^{1}$ Conforme estimativa do portal G1, disponível em http://g1.globo.com/brasil/protestos-2013/infografico/platb/.

${ }^{2}$ No exterior, 25 países participaram dos protestos, conforme dados do site Grunz em http://www.grunz.com.br/mapa-dos-protestos-no-brasil-pelo-mundo/. Foram eles Alemanha, Argentina, Austrália, Áustria, Bélgica, Bolívia, Canadá, Coréia do Sul, Dinamarca, Espanha, Estados Unidos, Finlândia, França, Holanda, Israel, Itália, Japão, México, Noruega, Peru, Portugal, Reino Unido, República Tcheca, Suécia e Suíça.
} 
SANTOS, G. S.

\#Vemprarua: jornadas de um espaço em rede

Figura 1 - Localização dos protestos por cidade e estado ${ }^{3}$
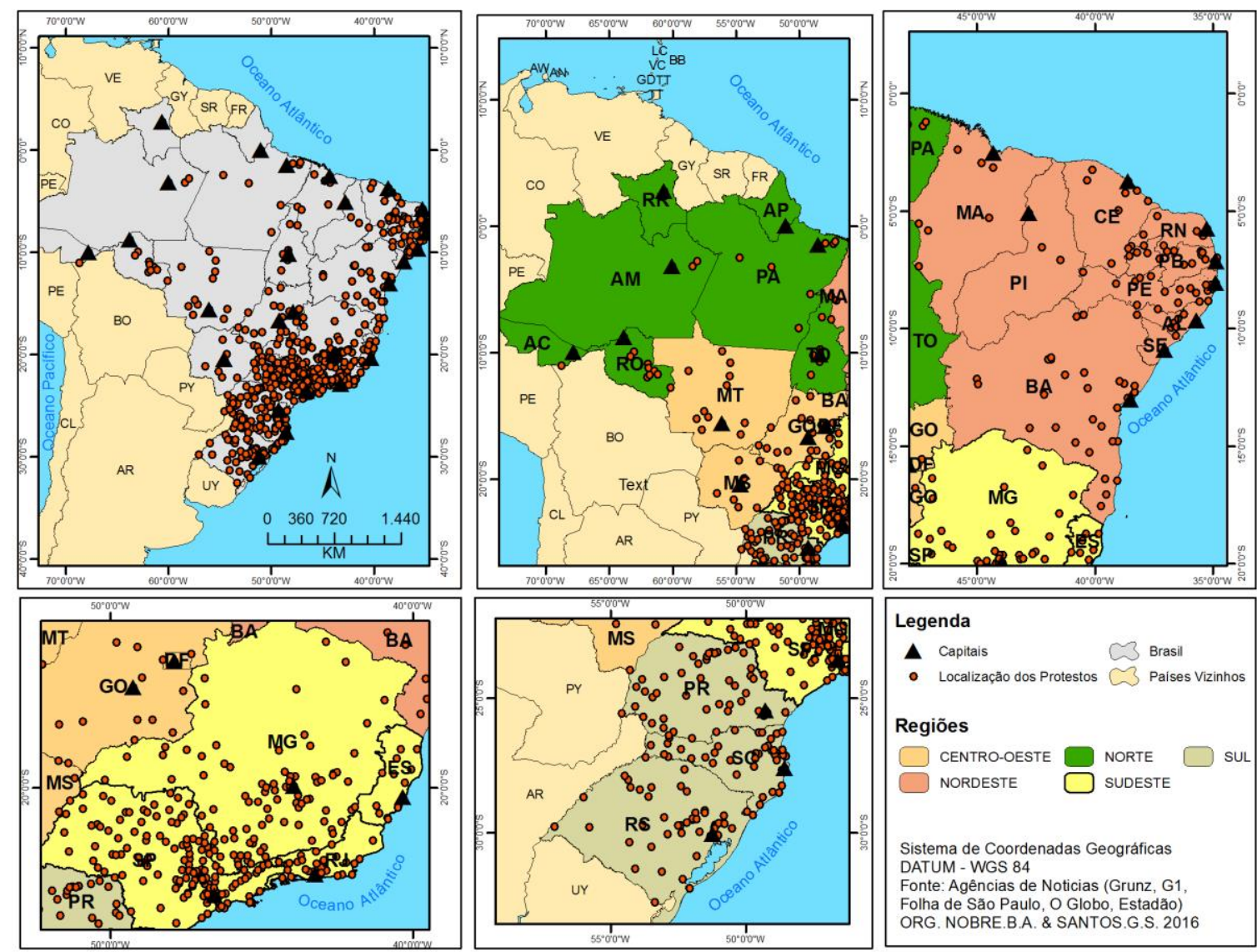

Fonte: Grunz, G1, Folha de S. Paulo, O Estado de S. Paulo e O Globo

A materialidade e a imaterialidade que compuseram as dinâmicas socioespaciais da mobilização se fundamentaram não apenas em fixos e fluxos convencionais, mas se depararam com um processo de refletância on-line e off-line. O postulado de Castells (2013) na abertura desta seção - é uma chave de leitura para o fenômeno complexo e composto por camadas das jornadas de junho. $\mathrm{O}$ debate cresce quando se considera que os movimentos sociais são eminentemente transformadores, isto é, sua carga de sentido e aplicação não se desenrola sem provocar revoluções, intervenções ou alterações no seio social.

Ao questionar cenários e articular agendas, os movimentos sociais introjetam dinâmica à ordem social vigente, seja pela interrupção, quebra ou subversão dos circuitos convencionais. É parte da essência da insurgência provocar rupturas e instaurar processos que

${ }^{3}$ Conforme Santos (2017).

Revista Cerrados, Montes Claros/MG, v.17, n. 1, p. 240-255, jan./jun.-2019. 
SANTOS, G. S.

\#Vemprarua: jornadas de um espaço em rede

chacoalham a ideia de ordem estabelecida, lançando luzes sobre diversos recortes, feridas e contradições que marcam a tessitura social.

Como uma mobilização de contestação e denúncia da realidade, os movimentos se entrincheiram por meio da autonomia e da performance alternativa. Isto é, rechaçam meios e métodos dos quais o poder constituído se respalda e se atrelam a atividades submersas de insubordinação e primam pelo alternativo como forma de contra poder.

Aqui se incluem o aporte das redes sociais e as possibilidades que a internet proporcionou aos manifestantes, ao movimento em si e aos cenários que se desenvolveram durante a trajetória. A internet permite uma comunicação ágil, autônoma e livre no que tangem discursos, interações e engajamentos. Na floresta de signos digitais, os atos se imiscuíram dos nós, arcos e fluxos que as redes digitais ofereciam entre plataformas, recursos e dispositivos.

A trajetória on-line das jornadas de junho pode ser entendida como indumentária de insurgência, isto é, roupagem e couraça que se adere à corporeidade da manifestação, implicando no delineamento de sua intenção e força. É necessário reiterar que a operação online do movimento se articula com a operação off-line para legitimar um ativismo que se expande para além do discurso.

Aos movimentos sociais são reservados os tratamentos discursivos de rebeldia, transtorno, reação, revolução, insubordinação e volatilidade. Entretanto, nesse prisma simbólico, a liberdade é que caracteriza o modus operandi e o modus vivendi dos movimentos sociais, abarcando em si os termos anteriores. A liberdade da insurgência implica em uma comunicação autônoma, decisiva para a experiência sociopolítica que os movimentos produzem e desencadeiam.

Movimentos sociais têm relação intrínseca com o espaço. Para que sua mensagem se dissemine, seu conteúdo se difunda e sua ação produza efeitos, é preciso que os atos insurgentes agenciem as formas espaciais e nela produzam vínculos e comunidades, as quais são a base do encadeamento da ação insurgente que se processa coletiva, engajada, solidária e ativamente. A proposta deste estudo é refletir as dinâmicas das Jornadas de Junho, considerando a dimensão do ciberespaço como elemento aglutinador de práticas socioespaciais e de insurgência, na busca de uma aproximação entre Geografia e ciberespaço no contexto do exame do caso em questão. 
SANTOS, G. S.

\#Vemprarua: jornadas de um espaço em rede

\section{DESENVOLVIMENTO}

Este estudo designa um estudo de caso das Jornadas de Junho de 2013, investigando suas dinâmicas de produção, tendo a análise socioespacial como elemento balizador (SANTOS, 2017). Discute-se um movimento social de um episódio nacional cuja repercussão multiescalar trouxe conjecturas por todo o país, como previamente sustentado. $\mathrm{O}$ movimento, notável por sua ativação, produção e difusão espacial, teve por estrutura arregimentadora o ciberespaço, isto é, o usufruto dos recursos, dispositivos, sociabilidades e performances on-line das redes sociais em reflexo e complemento à operações off-line, isto é, observáveis nos espaços públicos e urbanos.

Desse modo, fundamentando-se na categoria analítica de espaço (SANTOS, 2002; CORRÊIA, 1982) e, a partir dela, o conceito de rede (CASTELLS, 2013) e ciberespaço (LÉVY, 1998; 2000; LEMOS, 2015, concentrou-se esforço em uma leitura do movimento que considerasse sua dinâmica socioespacial partindo de sua reticulação que foi simultaneamente on-line e off-line. Esta perspectiva permite lançar lume sobre o ciberespaço, suas operações, recursos e práticas como elementos de agência, potência e iminência socioespacial. Trata-se de pensar geograficamente um movimento social fatídico a partir de sua construção virtual, fluida e (i)material.

Conforme Castells (2013), em sua base, os movimentos sociais precisam se constituir construindo um espaço público composto por comunidades livres no espaço urbano. Considerando que o espaço público institucionalizado detém marcas e os estandartes de interesses dominantes dos quais se faz objeção, é preciso abrir novos canais e vias. A criação desses novos espaços e sua apropriação é determinante para a mudança social, pois atingem a realidade de dentro para fora, de sua base para sua forma, de sua função para sua práxis.

Estas vias e este espaço público livre com comunidades livres se organizam por meio dos lugares visíveis, amplamente observáveis na paisagem urbana, e os invisíveis, no campo da representação e nas conexões promovidas pela internet. Estes espaços se desenvolvem a partir de três aspectos: noção comunitária, significação e politização (CASTELLS, 2013). Os movimentos sociais criam comunidade. O engajamento que as causas e agendas engendram só o faz mediante a aproximação de sujeitos em sua unidade e pluralidade. A consciência que motiva a insurgência gera vínculos e os vínculos são essenciais na produção de um engajamento que respalda a luta. Os laços que se firmam no 
ideário de luta são elementos de coesão, no entanto, auxiliam a delimitar a distância entre o pleito e a realidade.

Em junho de 2013, a pluralidade de vozes e cenários a partir dos quais os manifestantes se unificaram foi marcada por uma relação multiescalar de proximidade. A noção de distanciamento pelas diferentes escalas, demandas, espacialidades e temporalidades poderia ser motivo de dispersão. No entanto, a coesão em torno da unidade na diversidade construiu-se a partir de uma noção solidária, que por sua vez, se efetivou pela identificação causal entre os sujeitos, suas vivências e identidades.

A significação desses espaços de insurgência é determinante para sua articulação. Não há carência de significado no desencadeamento das mobilizações, uma vez que a ação, a resistência e as experiências em torno das manifestações são carregadas de poder simbólico. Tal poderio é determinante para a fecundidade da experiência sociopolítica do evento, gerando aderência entre sujeitos, fortalecendo sua prerrogativa e permitindo que sua ação perpasse barreiras e entraves cuja ruptura é desejada.

A jornada brasileira é carregada de significados desde sua eclosão. As alcunhas de “o gigante acordou”, "vem pra rua” e "não é por R\$ 0,20, é por direitos", entre tantos cartazes e marcadores de identificação consistiram em linhas de força da mensagem de protesto. $\mathrm{O}$ simbolismo presente nas ações, nas mensagens escritas e verbalizadas, e os gestos de ida às ruas não só integram o discurso, como dimensionaram a horizontalidade do poder ali elaborado.

A partir de uma noção comunitária que promove engajamento e da carga simbólica que adensa as relações no interior dos movimentos sociais, cumpre que seu espaço seja politizado. Isto implica que os conteúdos humanos, isto é, as vivências e experiências dos sujeitos passam a consistir um material social específico e nutrido no processo de insurgência, criando um esteio de debate, deliberação e luta.

As pautas levadas às ruas congregaram outros sujeitos e espaços à ação, seja por identificação, por consonância ou por estímulo. Tal despertar promoveu uma derrocada de atos, vozes e ações objetivando por meio da luta social a transformação da realidade. Por meio desta filiação sociopolítica, a coletividade de manifestantes se dirigiu às autoridades, a seus pares e ao conjunto social, interpelando sobre suas condições e toda sorte de demandas vocalizadas no fatídico mês de junho. 
SANTOS, G. S

\#Vemprarua: jornadas de um espaço em rede

As jornadas de junho se efetivaram como uma mobilização híbrida entre as redes digitais e o espaço urbano, entrelaçando de modo intempestivo o ciberespaço ao urbano "numa interação implacável e constituindo, cultural e tecnologicamente, comunidades instantâneas de prática transformadora" (CASTELLS, 2013, p. 20). Disso concorda Pierre Lévy, afirmando que o ciberespaço é o esteio cotidiano das operações da atividade humana na contemporaneidade $^{4}$. Nesse sentido, desprende-se um plano de análise perpassado de fenômenos que flexionam ante ao objeto comunicacional e técnico.

Ora, convém dirigir o olhar sobre o ciberespaço e seu préstimo como espaço reticulado. A origem do termo ciberespaço é literária e se popularizou na ficção científica de William Gibson em seu Neuromancer de 1984, cuja definição se situa na hipernarrativa de uma:

[...] alucinação consensual vivida diariamente por bilhões de operadores autorizados, em todas as nações, por crianças aprendendo altos conceitos matemáticos... Uma representação gráfica de dados abstraídos dos bancos de dados de todos os computadores do sistema humano. Uma complexidade impensável. Linhas de luz abrangendo o não-espaço da mente; nebulosas e constelações infindáveis de dados. Como marés de luzes da cidade (GIBSON, 2016, p. 67).

Todavia, a definição de Gibson pontua o ciberespaço como uma experiência incomum, com desencaixe da realidade pontual de vivência dos sujeitos e das sociedades. A clarividência, assim, vem com Lévy (2000, p. 92) que postula o ciberespaço como um "espaço de comunicação aberto pela interconexão mundial dos computadores e das memórias dos computadores". O filósofo francês ainda continua:

Essa definição inclui o conjunto dos sistemas de comunicação eletrônicos (aí incluídos os conjuntos de rede hertzianas e telefônicas clássicas), na medida em que transmitem informações provenientes de fontes digitais ou destinadas à digitalização. Insisto na codificação digital, pois ela condiciona o caráter plástico, fluido, calculável com precisão e tratável em tempo real, hipertextual, interativo e, resumindo, virtual da informação que é, parece-me, a marca distintiva do ciberespaço. Esse novo meio tem a vocação de colocar em sinergia e interfacear todos os dispositivos de criação de informação, de gravação, de comunicação e de simulação. A perspectiva da digitalização geral das informações provavelmente tornará o ciberespaço o principal canal de comunicação e suporte de memória da humanidade a partir do próximo século (LÉVY, 2000, p. 92-93).

\footnotetext{
${ }^{4}$ Trecho da fala de Pierre Lévy em palestra de outubro de 1994 no evento Festival Usina de Arte e Cultura em Porto Alegre/RS. Conferir em: https://www.nescon.medicina.ufmg.br/biblioteca/ imagem/2514.pdf. Acesso em: 24 nov. 2017.
}

Revista Cerrados, Montes Claros/MG, v.17, n. 1, p. 240-255, jan./jun.-2019. 
Nesse sentido, o ciberespaço diz de um esteio de comunicação, tal qual os meios de comunicação já experimentados e amplamente conhecidos, que surge e se estabelece a partir da interconexão de computadores (LEMOS, 2015). Essa definição não implica apenas na infraestrutura técnica e material que sustenta a comunicação digital funcionalmente, mas contempla o contingente de informações que circula por suas vias, bem como os sujeitos que nelas trafegam e suas práticas (LÉVY, 2000).

Em Lemos (2015) e Lévy (2000), há o apontamento do despontar da microinformática nas bases de surgimento do ciberespaço. A partir da década de 1970, com o avanço dos computadores pessoais, coletivos e a internet, o ciberespaço passa a ganhar tônus e significação, passando de uma representação futurista a uma demanda social legítima e, que paulatinamente, ganhava contornos para além das especificidades materiais que evocava.

O lema da microinformática se consolidou como "computadores para o povo" (ou computer to the people), o que foi determinante para que sua agenda se consolidasse socialmente. $\mathrm{O}$ avanço da comunicação informática passou a ensejar um ritmo colaborativo, cooperativo e coletivo. Isto é, um movimento internacional de entusiastas sobre o poder que emanava desta nova realidade, o poder tecnocrático, passou a desencadear incrementos e melhorias velozes.

A informática torna-se eminentemente social, ou seja, passa a se consolidar como uma plataforma de socialização de funcionalidades, ou determinada a produzir colaboração e penetrar os espaços cotidianos, em oposição à característica fechada e não acessível dos computadores iniciais e da própria internet. Uma vocação tenra à sociabilidade e à aplicabilidade aderente às condições da realidade. Lemos (2015, p. 99) esclarece:

\footnotetext{
A informática será uma ciência [...] da produção, organização, armazenamento e distribuição automatizada da informação, agora traduzida em bits [...]. A informática é, assim, uma forma de aliar o conhecimento da natureza às formas de funcionamento da sociedade moderna. Cria-se a possibilidade de leitura da realidade, traduzida pela linguagem digital, automatizando a informação.
}

$\mathrm{Na}$ trajetória de desenvolvimento da microinformática e dos computadores pessoais com a prerrogativa de apropriação e difusão popular, é a conexão ou a socialização das funções e papéis da informática o próximo passo com o computador conectado. Nesse ínterim, o desenvolvimento da internet torna-se emblemático, já que ela não apenas estabelece 
SANTOS, G. S

\#Vemprarua: jornadas de um espaço em rede

ligações entre sujeitos e máquinas, mas reduz as distâncias entre os sujeitos e a informação, promovendo intercâmbios e a difusão de conteúdo de modo social.

A primeira concepção da microinformática é estritamente técnica e produtiva, uma vez que o maquinário será um produto de referência e imitação do cérebro humano. Posteriormente, a meta se torna outra: a ampliação da linguagem e da transmissão. A automatização de processos e a transmissão de dados se tornam marcantes, criando redes sistêmicas de acesso e difusão de informações. Finalmente, chega-se à proposta de fortalecimento da sociabilidade em rede, por meio de comunidades eletrônicas.

A revolução antes técnica, material e radicada à transmissão imaterial torna-se sobremaneira um estágio de operações (i)materiais, onde os processos lógicos, de infraestrutura e de práticas relacionais tornam-se um híbrido de definição do que a microinformática passaria a evocar em seu curso histórico e, como interessa a esta discussão, o tônus de definição e significado de impacto do ciberespaço.

Ciberespaço passa a designar, assim, uma conjuntura onde opera uma estrutura material e lógica de conectividade, na qual se produzem e difundem informações em afluxo por sujeitos que, por sua vez, desenvolvem relações e práticas diversas, desenvolvendo uma malha, uma rede de ação e atuação, um sistema de sociabilidade particularizado pela ubiquidade e pelas operações on/off-line.

Com estes arranjos, Lévy (2000) aponta três pulsões que constituem e ao mesmo tempo movem o ciberespaço: a interconexão de dispositivos e pessoas, a coletividade elaborada na emancipação de comunidades virtuais e o desenvolvimento da inteligência coletiva. Estas pulsões aliadas à trajetória de desenvolvimento do ciberespaço, que tem origem axial na história da microinformática, lançam bases para a compreensão do ciberespaço como um eixo contemporâneo de compreensão da sociedade, cuja proposta deste trabalho se assenta e que respaldam o título que abre este subcapítulo.

A interconexão é o principal atributo do ciberespaço - e essencialmente da noção contemporânea de informática. Designa a ligação dinâmica e funcional entre dispositivos, linguagens, equipamentos e sistemas, bem como as inter-relações destes com os sujeitos que neles operam e interagem produzindo práticas diversas de comunicação e socialização. $\mathrm{Na}$ interconexão de dispositivos e sujeitos está o condicionamento do ciberespaço, uma vez que este se organiza e se sustenta na capacidade de comunicação e integração de linguagens de programação, armazenamento de informações, relações de produção, consumo e Revista Cerrados, Montes Claros/MG, v.17, n. 1, p. 240-255, jan./jun.-2019. 
SANTOS, G. S

\#Vemprarua: jornadas de um espaço em rede

compartilhamento de conteúdo. Conectar, prover conexão e conectar-se tornam-se atributos de uma modalidade de navegação social por meio do ciberespaço (SANTOS et al., 2015).

Estabelecer ligações lógicas entre máquinas-máquinas, máquinas-sujeitos e sujeitos-sujeitos indica um processo de complexificação dos elos humanos entre seus pares e para com os objetos que povoam a realidade. A interconexão promovida no ciberespaço é ubíqua, imaterial e virtual, isto é, não tem seu ocaso na materialidade, o que transforma as formas como são concebidos elos sociais e simbólicos entre sujeitos e objetos, produzindo novas camadas relacionais.

Se a interconexão estabelece ligações e elos, estes são prolongados pela segunda pulsão: as comunidades virtuais. Comunidade designa, naturalmente, a unidade de sujeitos adensada por um objetivo, identidade ou significado partilhado. No ciberespaço, as comunidades continuam designando constructos sociais, porém reorganizados.

As comunidades virtuais, conforme Lévy (2000), são construções socioculturais erigidas na extensão do ciberespaço, a partir de afinidades, projetos comuns e sentidos de pertencimento à rede, que se estabelecem por meio de trocas sem delimitação espaçotemporal. A interação é o certame destas comunidades que se apoiam na tele-existência e na telerrealidade, isto é, na performance virtual, para se fundamentar.

Sua manifestação é difusa e particular. Podem se estabelecer em núcleos que fomentam a colaboração, espaços criados para tal ou se estabelecer espontaneamente. Tem por estatuto relações colaborativas, construtivas, heterogêneas e recíprocas conforme seu ideário e proposta. As comunidades virtuais não são estritamente institucionais - embora o possam ser -, mas são marcadas pela consciência da pluralidade de sujeitos em rede e das possibilidades que esta interface comunitária pode promover.

Este senso comunitário leva à terceira pulsão chamada por Lévy (2000) como o espírito da cibercultura ou sua meta e lugar de realização. A inteligência coletiva é a sintaxe das operações do ciberespaço. Em outras palavras, diz-se do constructo colaborativo e compartilhável de saberes entre os sujeitos em rede que tem por meta ou realização o melhoramento e o aprimoramento do próprio ambiente em rede (LÉVY, 1998).

A inteligência coletiva produz a tessitura essencial do ciberespaço: o enredamento e a conexão de sujeitos e dispositivos em uma malha difusa e una. O intercâmbio, as trocas simbólicas, a produção e o compartilhamento de informações se estabelecem como a 
SANTOS, G. S.

\#Vemprarua: jornadas de um espaço em rede

animação do ciberespaço, em que todas as ações possuem um princípio integrador, onde o incremento do próprio espaço de sua realização é ao mesmo tempo seu impulso motor.

Há que se destacar que a inteligência coletiva se estabelece ante um dilúvio informacional (LÉVY, 2000), isto é, a partir do contingente e fluxo de informações em rede. As práticas de difusão, compartilhamento, reparo, melhoramento e engajamento têm por princípios a interatividade - já característica das redes - e a liberdade, sem controle institucional estrito, mas na premissa de um domínio e interesse público.

A interconexão cria, viabiliza e consolida laços e elos, permitindo a produção e a manutenção de malhas e dinâmicas de ação e interação. Estas ações e interações constituem polos relacionais, capazes de concentrar as atividades e performances humanas em rede, originando núcleos, comunidades virtuais. Tais comunidades, por meio da sociabilidade e das conexões que lhe são características, produzem performances diversificadas, cujo princípio ulterior é a manutenção da própria rede em uma pluralidade de agendas.

As pulsões levynianas que caracterizam o ciberespaço o tornam um lócus espaçotemporal, isto é, um esteio articulado entre dispositivos, técnica e sujeitos a fundamentar uma dinâmica espacial regida pela virtualidade em consonância ao não-virtual (SANTOS; TRINDADE; ROCHA, 2015). Essa espacialidade virtual é aditivada pelas pulsões trazidas pelas conexões, pela coletividade em rede e a inteligência coletiva. Nesse sentido, desdobra-se mais do que um substrato perpassado por operações virtuais, mas um espectro dinâmico entre espacialidade, sociabilidade e reticulação.

$\mathrm{Na}$ alcunha do termo em questão, seja no fragor literário de Gibson seja na discussão levyniana, é possível decompor o ciberespaço em duas seções de análise geográfica: espaço e redes. O espaço como a operação funcional, (i)material e virtual, e redes como as múltiplas conexões e vias que se arrolam formando uma malha on-line/off-line. Nessa perspectiva, lançando-se lume geográfico, espaço e rede se efetivam como dados epistemológicos e se anelam para constituir, organizar e explicitar a emergência e os fenômenos atrelados ao ciberespaço.

Espaço e rede como descritores do ciberespaço o posicionam como um modelo espacial reticulado, isto é, que opera sua espacialidade e dinâmicas espaciais em redes. Em última instância, o ciberespaço - pela cadência da informação que abarca e dos sujeitos que comporta - gera pontos rizomáticos, fluídos e neurais de espacialização conforme a diversificada tipologia de dispositivos e interfaces para tanto; pelas linguagens lógicas e a Revista Cerrados, Montes Claros/MG, v.17, n. 1, p. 240-255, jan./jun.-2019. 
ambiência on-line, códigos e hiperlinks se tornam traquejos de comunicabilidade; e pela sociabilidade que provoca e é provocado, fomenta práticas diversas.

As premissas da espacialidade, reticulação e sociabilidade - retomando as pulsões de interconexão, comunidades virtuais e inteligência coletiva (LÉVY, 2000) - do ciberespaço, tem-se um composto pertinente à compreensão do que os fenômenos atrelados a este "lugar onde a humanidade funciona hoje": a noção de cibercultura.

A cibercultura compreende as práticas socioculturais desenvolvidas no ciberespaço entre intercâmbios simbólicos, produtos e objetos culturais. Concentra as operações de produção de sentidos no ciberespaço, posicionando-se como um adensamento das performances, identidades, relações e fluxos perpetrados neste espaço reticulado, constituindo-se o aditivo e a fecundidade das realizações do ciberespaço.

Localizando as jornadas de junho neste prospecto, observa-se um movimento social caracterizado por práticas insurgentes desenvolvidas de modo on-line e off-line, isto é, tanto as práticas in loco, como as operações virtuais consistiram a insurgência dos atos desse evento. Não obstante, junho de 2013 revelou um movimento atrelado ao ciberespaço intrinsecamente e cujas práticas, performances, discursos e atos se desdobraram de articulações em torno da cibercultura.

Entender que o movimento se inscreve em uma articulação socioespacial particularizada pelo ciberespaço e adensada pela cibercultura, permite posicionar os objetos e as teorias de natureza geográfica em outro espectro, onde as dinâmicas espaciais, sociais, culturais, políticas e comunicacionais são componentes inerentes à constituição de fenômenos contemporâneos dessa natureza. "Em realidade, não há apenas novos objetos, novos padrões, mas, igualmente, novas formas de ação”, evoca Santos (2002, p. 62) ao se debruçar sobre a natureza do espaço. É nesta consideração miltoniana que o exame das jornadas de junho, a partir de sua operacionalização on-line/off-line, converge para a discussão da dimensão do espaço no ciberespaço, isto é, para uma geografia do ciberespaço.

Corrêa (1982, p. 32-34) discorre que "é, sobretudo, através da ação humana que o espaço desempenha um papel na sua organização" e, "enquanto [...] morada do homem, acreditamos ser necessário pensá-lo em termos de suas conexões com o tempo, pois tempo e espaço reúnem toda a experiência humana". Esta perspectiva de inter-relação dos sujeitos e a articulação temporal torna o espaço o acontecer de práxis, um espectro da simultaneidade do espaço-tempo. 
SANTOS, G. S.

\#Vemprarua: jornadas de um espaço em rede

Em junho de 2013, pode-se observar a produção de um espaço reticulado e multiescalar, a emergência de territorialidades insurgentes e a aquiescência de um espaço arraigado às práticas virtuais, cujos desdobramentos são pontuais, factuais e prontamente relacionados ao ambiente não virtual (FEIXA; FERNÁNDEZ-PLANELLS; FIGUERASMAZ, 2016). O ciberespaço, como abordado anteriormente, é uma modalidade espacial caracterizada pela interconexão de sujeitos e dispositivos, pela sociabilidade e pela coletividade corresponsável por sua (re)construção continuada. Embora as relações socioespaciais sejam subvertidas pela virtualidade no ciberespaço, as práticas desenvolvidas em sua ambiência participam da realidade socioespacial não virtual, sendo nela axial, modal e influente.

Na ocorrência frequente de tipificação do virtual e on-line como inválido, como se sua perspectiva fosse alheia à realidade fora de sua dimensão, é preciso discutir que o ciberespaço pode ser caracterizado como espaço produzido e produtivo. Isto é, dotado dos elementos, fluxos e variáveis que abarcam a polissemia espacial e se aglutinam no objeto de anelo geográfico.

Ora, a dimensão virtualizada e subversiva da materialidade - e da própria imaterialidade - do espaço não é obstáculo para posicioná-lo como conceito geográfico na senda do espaço como categoria de análise. Ao contrário, aproximar-se das propriedades do ciberespaço e das práticas nele desempenhadas é uma direção que toca a fragor do próprio conceito espacial, isto é, de seus objetos, fluxos, elementos fundantes e estruturantes.

Como fruto do desenvolvimento da microinformática, da interlocução entre os atores na própria malha - no que nomeia-se inteligência coletiva em Lévy (2000) -, da técnica, do resultado contínuo do aprimoramento dos sistemas funcionais entre lógicas humanas e artificiais e de sua própria definição, o ciberespaço se posiciona como espaço produzido e em produção.

O acesso e o uso da internet, a multiplicidade de dispositivos e aplicações customizáveis, o consumo e a difusão de informações, as interações desenvolvidas e o desenvolvimento do aparato em hardware, em software e em peopleware são práticas e ações de produção espacial localizados na ambiência do ciberespaço. Nesse sentido, além de espaço produzido e em produção, o ciberespaço é também espaço produtivo. Isto é, um lócus de múltiplas operações humanas, resultado de fixos e fluxos e desencadeador de processos cuja ação humana é eixo e empuxo. As jornadas de junho são testemunhais expressivos desta Revista Cerrados, Montes Claros/MG, v.17, n. 1, p. 240-255, jan./jun.-2019. 
SANTOS, G. S.

\#Vemprarua: jornadas de um espaço em rede

qualidade de espaço produtivo, uma vez que tal condição forneceu insumos para que o movimento e suas dinâmicas se desenvolvessem.

Como espaço produzido, producente e produtivo, o ciberespaço se arraiga à polissemia espacial descortinando novos cenários, arranjos e práticas. Nesse ínterim, a exploração da ambiência e do aparato do ciberespaço deixa de ser exótica e se torna corrente para a proposição de uma geografia que perscruta e revisita seus objetos.

Retomando o espaço como contingente da experiência humana em combinação ao tempo, é cadente posicionar o ciberespaço com suas práticas e propriedades como uma trilha investigativa, já que deflagra em si ações humanas e espaciais. Aproxima-se, deste modo de uma geografia que articula os signos e os dispositivos do ciberespaço, como partícipe deste sistema de objetos e sistema de ações, dotado de forma, função, estrutura e processos que é o espaço. Aproxima-se, enfim, de uma geografia que se abeira à subversão de conceitos e às narrativas da contemporaneidade, isto é, uma geografia do ciberespaço.

\section{CONSIDERAÇÕES FINAIS}

As jornadas de junho se constituíram como um movimento de insurgência disposto sobre o Brasil no período de junho de 2013, com base nas iniciativas do MPL em protesto contra a tarifa do transporte público em São Paulo, mas cujo escopo se ampliou e abarcou uma série de demandas sociais cuja origem é o âmago da sociedade brasileira na extensão e nas particularidades do território nacional.

As redes desempenharam um papel preponderante sobre a organização e sobrevida dos atos. O usufruto do ciberespaço como indumentária de protesto foi determinante para que a mobilização se constituísse como um ato de comunicação alternativo e autônomo, penetrando as barreiras midiáticas institucionalizadas para produzir suas próprias narrativas de contrapoder. Redes sociais, comunicação em tempo real, hashtags, imagens, vídeos e testemunhos fizeram emergir uma atmosfera de ação, reação, solidariedade e resistência.

Para a compreensão e tratamento dos movimentos sociais e outras tipologias de mobilização popular, fica evidente a necessidade de posicionar novas lentes de análise. A contemporaneidade tem encerrado novas vertentes, onde o estabelecido e o ordenado são subvertidos para a produção de novos sentidos. E estes novos sentidos produzidos são Revista Cerrados, Montes Claros/MG, v.17, n. 1, p. 240-255, jan./jun.-2019. 
voláteis, ágeis e provocam micro e macro revoluções cotidianas, tornando a quotidianidade um panorama ora de alvorecer ora de crepúsculo.

No que tocam as relações dos sujeitos com o espaço e da própria condição epistemológica e ontológica do espaço, há que se considerar a variabilidade sempre nova que a polissemia deste conceito/categoria dispensa. O espaço torna-se não apenas condição, baliza e um corpus social, mas a cobertura das interações sociais ou componente da performance humana, não como objeto alheio, mas em uma combinação de internalização e externalização.

Nesse sentido, uma variável torna ainda mais complexo o diálogo com o espaço na contemporaneidade: o ciberespaço. As práticas no ciberespaço já não compreendem as narrativas de sofisticação técnica ou utopia tecnocrática. É preciso aproximar do ciberespaço como um objeto cuja espacialidade é premente. Tornar as narrativas, elementos e performances em torno do ciberespaço em pontos de observação espacial, torna a ciência geográfica mais aberta e inserida na complexidade que o anelo de sua práxis se faz: o espaço.

\section{REFERÊNCIAS}

CASTELLS, M. Redes de indignação e esperança: movimentos sociais na era da internet. Tradução de Carlos Alberto Medeiros. Rio de Janeiro: Zahar, 2013.

CORRÊA, R. L. O espaço geográfico: algumas considerações. In: SANTOS, M. (Org.). Novos rumos da Geografia brasileira. São Paulo: Hucitec, 1982.

FEIXA, C.; FERNÁNDEZ-PLANELLS, A.; FIGUERAS-MAZ, M. Generación Hashtag. Los movimientos juveniles en la era de la web social. Revista Latinoamericana de Ciencias Sociales, Niñez y Juventud, v. 14, n. 1, p. 107-120, 2016.

GIBSON, W. Neuromancer. Tradução de Marcia Men. 5. ed. São Paulo: Aleph, 2016.

LEMOS, A. Cibercultura. Tecnologia e vida social na cultura contemporânea. 7. ed. São Paulo: Sulina, 2015.

LÉVY, P. A inteligência coletiva: por uma antropologia do ciberespaço. 3. Ed. São Paulo: Loyola, 1998.

LÉVY, P. Cibercultura. São Paulo: Editora 34, 2000.

SANTOS, G. S. et al. Cibercultura, interações sociais e pós-modernidade: realidade versus virtualidade. Espacios, Caracas, v. 36, n. 22, 2015. 
SANTOS, G. S. \#Vemprarua: territorialidades de insurgência e ativismos on-line/off-line nas Jornadas de Junho de 2013 no Brasil. 2017. 158f. Dissertação (Mestrado) - Programa de Pós-graduação em Geografia, Universidade Estadual de Montes Claros, Montes Claros, 2017.

SANTOS, G. S.; TRINDADE, L. T.; ROCHA, J. S. B. Um novo lócus espaçotemporal.

Animus - Revista Interamericana de Comunicação Midiática, Santa Maria, v. 14, n. 28, p. 171-186, 2015.

SANTOS, M. A natureza do espaço: técnica e tempo, razão e emoção. São Paulo: Editora da Universidade de São Paulo, 2002.

Gustavo Souza Santos - Possui graduação em Comunicação Social - Publicidade e Propaganda pelo Centro Universitário FIPMoc (UNIFIPMoc) e mestrado em Geografia pela Universidade Estadual de Montes Claros (UNIMONTES). Atualmente é doutorando do Programa de Pós-Graduação em Desenvolvimento Social da Universidade Estadual de Montes Claros (UNIMONTES) e é professor do Centro Universitário FIPMoc (UNIFIPMoc).

Artigo recebido em: 30 de janeiro de 2018.

Artigo aceito em: 30 de abril de 2019.

Artigo publicado em: 28 de junho de 2019. 